\title{
Candoluminescence of cave gypsum
}

\author{
John R. Sweet ${ }^{1}$, John W. Hess ${ }^{2}$, and William B. White ${ }^{3}$
}

\begin{abstract}
:
Sweet J.R., Hess J.W. and White W.B. 2010. Candoluminescence of cave gypsum. International Journal of Speleology, 39 (1), 25-28. Bologna (Italy). ISSN 0392-6672.

A selection of gypsum specimens from a variety of caves as well as $\mathrm{CaSO}_{4}$ synthesized in the laboratory emit both a green and yellow candoluminescence when excited by a hydrogen diffusion flame. The green emission is attributed to dehydration of gypsum to bassanite and the yellow emission appears upon further dehydration to anhydrite. The source of the luminescence is ascribed to minor concentrations of $\mathrm{Mn}^{2+}$ in the gypsum.
\end{abstract}

Keywords: Gypsum, anhydrite, bassanite, candoluminescence, cave

Received 16 October 2009; Revised 25 November 2009; Accepted 18 December 2009

\section{INTRODUCTION}

Candoluminescence is a form of luminescent emission excited by flames, usually diffusion (brush) flames of burning hydrogen. Interest in the subject has a long history going back to attempts to understand the light emitted from gas mantles in the late $19^{\text {th }}$ Century. This early work essentially ended when a major review article was published (Nichols et al., 1928). Following a lengthy hiatus, there was renewed interest in the 1970's motivated by interest in producing a more efficient incandescent light source (Ivey, 1974). Following our own early work on candoluminescence (Sweet et al., 1970; Hess et al., 1974), it seemed of interest to investigate candoluminescence in the Earth sciences (White, 1990). The present report deals with the candoluminescence of cave minerals, specifically gypsum and anhydrite.

Calcite, the most common mineral in caves exhibits a range of photo- and cathodo-luminescence depending on incorporated impurity ions and organic molecules (Shopov, 2004) but it has not been found to be candoluminescent. In contrast, gypsum from several localities emitted both green and yellow luminescence in the hydrogen flame but was inactive under UV excitation. The luminescence of gypsum is

1 Present address: 8562 Jackson River Road, Mustoe, VA 14468, USA

2 Present address: Geological Society of America, 3300 Penrose Place, Boulder, CO USA

3 Corresponding author: Materials Research Institute, Materials Research Lab. Bldg., The Pennsylvania State University, University Park, PA 16802, USA exceptional, first in that hydrated compounds are not usually luminescent and secondly in the low activator concentration required. The characterization of these phenomena is the subject of this paper.

\section{EXPERIMENTAL METHODS}

Table 1 lists the eleven cave gypsum samples examined and includes a laboratory gypsum used for comparison. As a reconnaissance, the minerals were tested by brushing them with a hydrogen flame and observing the luminescence visually. These minerals were also tested under UV excitation and under plasma excitation. Both long wave (365 nm) and short wave $(254 \mathrm{~nm}) \mathrm{UV}$ was tested. High energy (cathodo-) excitation was achieved by placing chips of the minerals in a test tube, pumping a weak vacuum, and exciting a gas plasma in the tube with a high frequency, high voltage vacuum leak detector. Table 1 summarizes the results.

Emission spectrographic analyses were obtained on three of the samples (Table 2). As expected, cave gypsum is quite pure except for silicon which may be present as traces of quartz. Manganese, the most likely candidate for a luminescence activator, is uniformly low, $10-25 \mathrm{mg} / \mathrm{kg}$. No other elements that might act as activators were detected.

The basic experimental setup is shown in Figure 1. The mineral sample was ground to a fine powder, slurried with water, and painted onto a Kanthal heating rod with a cooling jacket so that the phosphor temperature could be controlled independently of the flame. Tank hydrogen was burned in air at a small silica-glass jet to form a diffusion flame. The flame 
Table 1. Observations of luminescence in gypsum.

\begin{tabular}{|c|c|c|c|c|}
\hline Sample* & Description and Location & Candoluminescence & Cathodoluminescence & Photoluminescence \\
\hline $\mathbf{2 7 9}$ & Crusts, Fitton Cave, Arkansas & Bright green & None & None \\
\hline $\mathbf{3 4 8}$ & Crystals, Fitton Cave, Arkansas & Bright green & None & None \\
\hline $\mathbf{7 0 1}$ & Needles, Cumberland Caverns, Tennessee & Green & None & None \\
\hline $\mathbf{1 1 5}$ & Massive crystals, Cumberland Caverns, Tennessee & Faint green & Spots of green & None \\
\hline $\mathbf{2 2 9}$ & Crusts, Wind Cave, South Dakota & Faint green & Faint green & None \\
\hline $\mathbf{2 5 4}$ & Crusts, Wind Cave, South Dakota & Green & Faint pinkish & None \\
\hline $\mathbf{3 0 2}$ & Crusts, Butler Cave, Virginia & Green & None & None \\
\hline $\mathbf{7 4 7}$ & Dark crystals, Gypsum Cave, Texas & Green & None & None \\
\hline $\mathbf{7 4 7}$ & White crystals, Gypsum Cave, Texas & Green & Faint pinkish & None \\
\hline $\mathbf{4 1 4}$ & Crusts, Turner Ave., Mammoth Cave, Kentucky & Faint green & Faint pinkish & None \\
\hline & Gypsum bedrock, Parks Ranch Cave, New Mexico & Bright green & None & Bright green \\
\hline
\end{tabular}

*Sample numbers refer to a reference collection of cave material maintained by the corresponding author. Photoluminescence examined with both long and short wavelength ultraviolet excitation.

Table 2. Results of emission spectrographic analysis of gypsum samples

\begin{tabular}{|c|c|c|c|c|c|c|c|}
\hline Sample & Description & $\mathbf{M g}$ & $\mathbf{A l}$ & $\mathbf{S i}$ & $\mathbf{T i}$ & $\mathbf{F e}$ & $\mathbf{M n}$ \\
\hline $\mathbf{1 1 5}$ & Massive crystals & $40-70$ & $80-100$ & Minor & $50-75$ & $20-50$ & $10-25$ \\
\hline $\mathbf{2 7 9}$ & Gypsum crust & $10-20$ & n.d. & Major & n.d. & $5-10$ & $10-25$ \\
\hline $\mathbf{1 4 2 5}$ & Gypsum bedrock & $20-40$ & $20-40$ & $200-400$ & n.d. & $5-10$ & $10-25$ \\
\hline
\end{tabular}

n.d. = not detected. Detection limits vary but are less than $1 \mathrm{mg} / \mathrm{kg}$. Elements sought but not detected: $\mathrm{Cr}, \mathrm{Ni}, \mathrm{V}, \mathrm{Cu}, \mathrm{Zr}, \mathrm{Be}, \mathrm{Mo}, \mathrm{Ag}, \mathrm{Yb}, \mathrm{Y}, \mathrm{Ge}, \mathrm{Sb}$, $\mathrm{Ga}, \mathrm{In}, \mathrm{Bi}, \mathrm{Sn}, \mathrm{Gd}, \mathrm{Zn}$

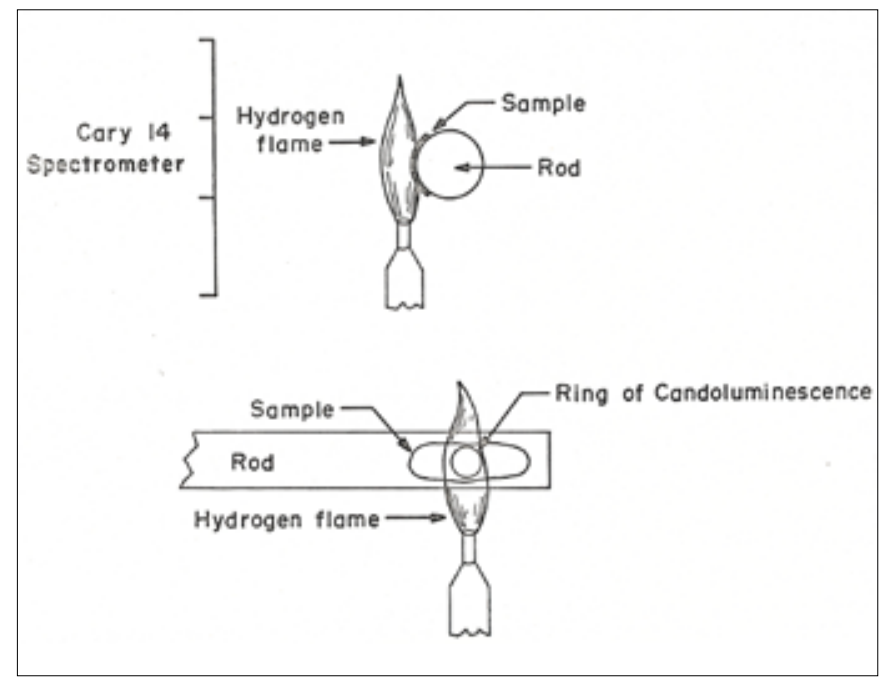

Fig. 1. Experimental set-up for measuring candoluminescence spectra.

was played over the sample and the emitted light focused onto the entrance slit of a Cary Model 14 spectrophotometer. Spectra were recorded directly by using the instrument in single beam mode.

The emission of the flame itself was measured by moving it slightly toward the spectrometer just barely out of contact with the sample. The flame spectrum consisted of a faint continuum and a cluster of strong lines near $580 \mathrm{~nm}$ arising primarily from $\mathrm{Na}$ and $\mathrm{Ca}$ in the flame. This background has been subtracted from the spectra shown in the figures and also a correction factor for photomultiplier response has been included.

The temperature dependence of the luminescence could be measured with the same setup by first setting the Cary monochromator to the wavelength of the emission peak and recording intensity while cycling the temperature up and down. Temperatures were recorded directly using a chromel-alumel thermocouple.

Phase purities of the samples before and after exposure to the hydrogen flame were determined by $\mathrm{X}$-ray diffraction. The powder samples were prepared for the diffractometer on a special silica glass slide and the X-ray patterns measured. Then the slide and sample were heated in the flame, immediately returned to the diffractometer, and re-measured.

\section{RESULTS}

Screening tests on the collection of cave gypsum samples from various locations (Table 1) showed that all produced at least a weak candoluminescent emission and no photoluminescence. All showed the same green candoluminescence upon brief exposure to the flame, although the intensity varies markedly among the samples. A few of the samples gave a faint pink cathodoluminescence and two showed very pale spots of green, much weaker than the green excited by the flame.

The spectrum of the green emission (Fig. 2) consists of a broad band peaking near $540 \mathrm{~nm}$. The peak wavelength varies somewhat from sample to sample. The spectra in Figure 2 have been smoothed; the original spectrometer plots contain considerable noise due to flicker in the flame during the time required for the spectra to be scanned. 
The green emission appears with only brief heating of the samples in the flame. Upon extended heating, the green luminescence gave way to a bright lemon yellow emission. The spectrum of the yellow emission (Fig. 3) is a smooth symmetrical band with a peak wavelength of $580 \mathrm{~nm}$. When a gypsum sample was heated in the flame just sufficiently to develop a uniform green emission, its X-ray diffraction pattern indicated a mixture of bassanite $\left(2 \mathrm{CaSO}_{4} \cdot \mathrm{H}_{2} \mathrm{O}\right)$ and anhydrite $\left(\mathrm{CaSO}_{4}\right)$ with only traces of the original gypsum remaining. The green emission appeared quickly and persisted for some minutes under continuing excitation. When the same sample was further heated to achieve a uniform yellow emission, the resulting X-ray pattern indicated a pure anhydrite phase. After cooling, the green emission did not immediately recur, but did recur after the sample remained in the laboratory over night.

The cathodoluminescence of the bassanite phase was found to be green, very similar to the flameexcited emission. The anhydrite phase yielded a more orange emission under cathodo-excitation. Anhydrite that was allowed to absorb atmospheric moisture overnight luminesced green indicating that it had rehydrated only to the bassanite phase.

To pursue the hypothesis that the activator for the luminescence was $\mathrm{Mn}^{2+}$, two synthetic samples were prepared. For sample A, 20 grams of gypsum were boiled for three one hour intervals in $250 \mathrm{~mL}$ of an aqueous solution containing first 1 , then 2 and then 4 grams of $\mathrm{MnSO}_{4}$. The solutions were filtered between intervals to extract the solids before transferring the solids back into the next most-concentrated solution. Measurement of the samples at each interval gave the same intensity green candoluminescence. Sample B was prepared by a solid state reaction between gypsum and $\mathrm{MnSO}_{4} \cdot \mathrm{H}_{2} \mathrm{O}$. The components were ground together and fired at $780-810{ }^{\circ} \mathrm{C}$ for 13 hours, then reground, and fired again for 2.75 hours to produce a compound with the composition $\mathrm{Ca}_{0.95} \mathrm{Mn}_{0.05} \mathrm{SO}_{4}$. Sample A produced first green, then with increased temperature a bright yellow candoluminescence. Sample B produced only the bright yellow candoluminescence. Neither sample was photoluminescent.

A characteristic of candoluminescence is that the brightness exhibits a pronounced maximum at some temperature in the range of a few hundred degrees centigrade. The temperature dependence of the intensity of the yellow luminescence was measured for samples A and B (Fig. 4). The spectra of these two samples are similar but the temperature dependences of the peak intensities are quite different. Sample A delivered peak brightness near $150{ }^{\circ} \mathrm{C}$ while peak brightness for sample B occurs near $375{ }^{\circ} \mathrm{C}$. In addition, greater absolute intensities were achieved during the cooling cycle rather than during the heating cycle. All curves were reproducible to a fair degree, implying that the difference should be ascribed to the samples themselves and are not a measurement artifact.

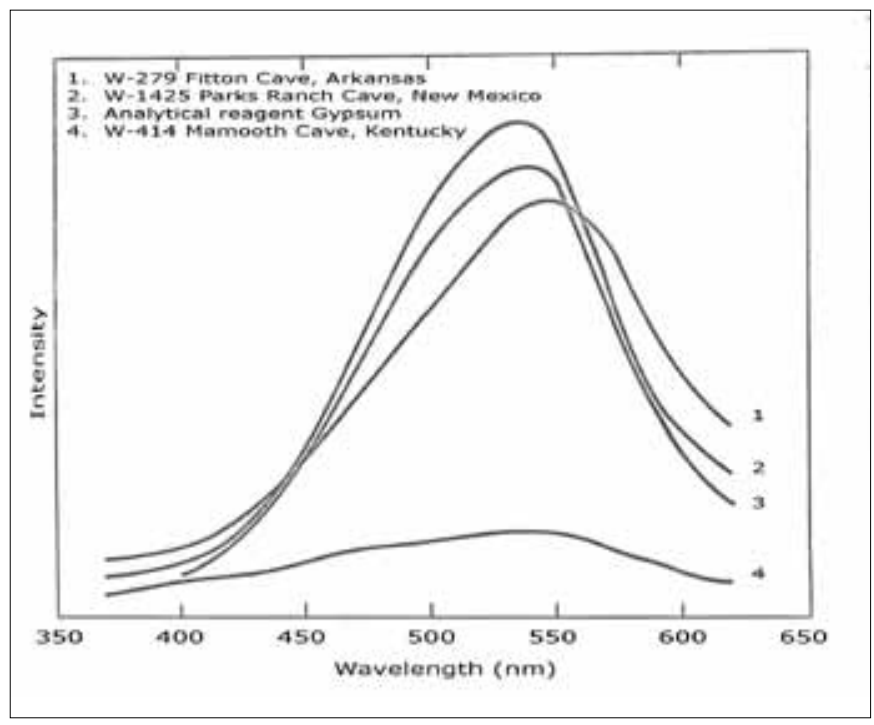

Fig. 2. Candoluminescence spectra for several gypsum specimens. Spectra measured with Cary-14 spectrophotometer; slit $=3 \mathrm{~mm}$. Flame background has been subtracted and photomultiplier response corrected.

1. 279 , Fitton Cave, Arkansas

2. 1425 , Bedrock from Parks Ranch Cave, New Mexico

3. Laboratory gypsum

4. 414, Turner Avenue, Mammoth Cave, Kentucky

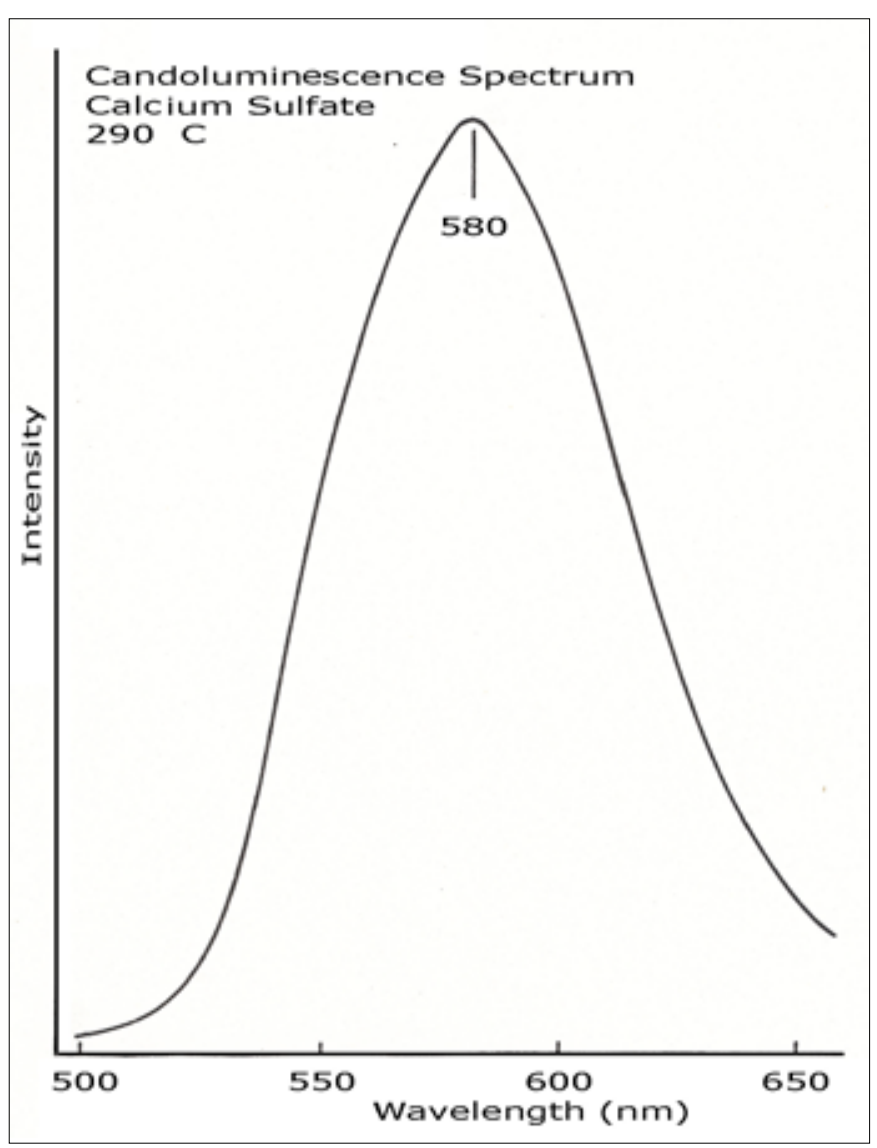

Fig. 3. Emission spectrum of the bright yellow candoluminescence of anhydrite. The spectrum has been smoothed to eliminate noise due to flame flicker. Measurement taken at $290^{\circ} \mathrm{C}$.

\section{DISCUSSION}

The results presented above suggest that at least a surface layer of the powdered gypsum dehydrates in the flame to initially produce bassanite which emits the green luminescence. Further heating produces 


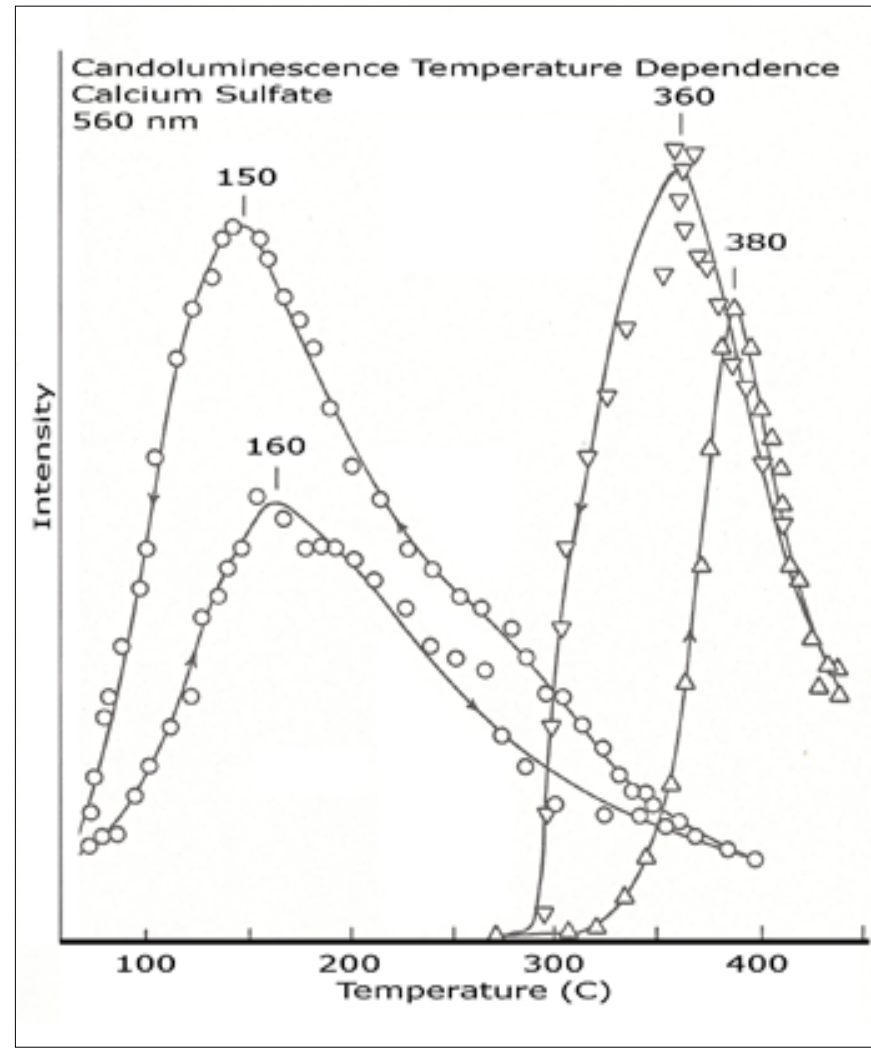

Fig. 4. Temperature dependence of yellow candoluminescence of $\mathrm{Mn} 2+$-doped anhydrite. Circles are sample A; triangles are sample B. Arrows indicate heat-up and cool-down cycles.

additional dehydration to the anhydrite phase which emits the bright lemon yellow luminescence. The activator ion appears to be $\mathrm{Mn}^{2+}$ in spite of its low concentration in the cave gypsum samples.

The photoluminescence due to $\mathrm{Mn}^{2+}$ ion is very sensitive to details of the crystallographic site that it occupies and varies from green when it substitutes for $\mathrm{Zn}^{2+}$ in willemite $\left(\mathrm{Zn}_{2} \mathrm{SiO}_{4}\right)$ to a crimson red in spinel $\left(\mathrm{MgAl}_{2} \mathrm{O}_{4}\right)$ (White, 1990). The observed yellow emission at $580 \mathrm{~nm}$ in $\mathrm{CaSO}_{4}$ is close to the $594 \mathrm{~nm}$ emission of $\mathrm{Mn}^{2+}$ in lime $(\mathrm{CaO})$. In both compounds, $\mathrm{Mn}^{2+}$ would have substituted for $\mathrm{Ca}^{2+}$ in the host structure. The absence of photoluminescence in any of the samples including those deliberately doped with additional $\mathrm{Mn}^{2+}$ is due to the absence of a co-activator that would serve to transfer the UV photons to the $\mathrm{Mn}^{2+}$ ion. Calcite, likewise, requires a co-activator for $\mathrm{Mn}^{2+}$ photoluminescence.

The energy source for candoluminescence is the recombination of radicals in the flame on the mineral surface. The recombination energy is transferred to the luminescence center where it is emitted as the observed candoluminescence. Possible recombination reactions in the hydrogen flame include:

$$
\begin{array}{ll}
\mathrm{OH}^{*} \rightarrow \mathrm{OH} & 4.03 \mathrm{eV} \\
\mathrm{H}+\mathrm{H} \rightarrow \mathrm{H}_{2} & 4.31 \mathrm{eV} \\
\mathrm{H}+\mathrm{OH} \rightarrow \mathrm{H}_{2} \mathrm{O} & 5.5 \mathrm{eV} \\
\mathrm{OH}^{*}+\mathrm{H} \rightarrow \mathrm{H}_{2} \mathrm{O} & 9.17 \mathrm{eV}
\end{array}
$$

$\mathrm{OH}^{*}$ is an excited state of the $\mathrm{OH}$ radical. The energy of short wave UV $(253.7 \mathrm{~nm})$ is $4.89 \mathrm{eV}$. Because the observed bright candoluminescence requires an efficient energy transfer, it seems likely that the $9.17 \mathrm{eV}$ reaction is the excitation source.
The other radical recombinations inject energies similar to that of short wave UV. If they were responsible for the candoluminescence, the absence of photoluminescence becomes difficult to explain.

The maximum in candoluminescence brightness as a function of temperature has been ascribed to the absorption and desorption of the active species from the mineral surface. As the temperature increases, absorbed species are desorbed, exposing fresh surface to the active radicals in the flame. The efficiency of the energy transfer increases until the temperature reaches a value sufficiently high to desorb the active species and thus the emission decreases at higher temperatures. In some systems, thermal quenching of the mineral itself may contribute to the high temperature limb of the brightness curve. Because the adsorption and interaction of flame species is highly dependent on details of the mineral surface, the temperature response of the two synthetic samples, A and $\mathrm{B}$, are quite different.

\section{CONCLUSIONS}

After experimenting with a number of cave minerals exposed to hydrogen flames, it was found that gypsum from many cave localities is strongly candoluminescent. At lower temperatures, the emission is a bright green as the gypsum is dehydrated to bassanite. At higher temperatures, a bright lemon yellow candoluminescence appears as the bassanite is further dehydrated to anhydrite. The luminescence is ascribed to tens of $\mathrm{mg} / \mathrm{kg} \mathrm{Mn}^{2+}$ that occurs as an impurity in the gypsum.

\section{ACKNOWLEDGEMENTS}

Research on candoluminescence was supported by the Pennsylvania Science and Engineering Foundation.

\section{REFERENCES}

Hess J.W., Sweet J.R. \& White W.B., 1974 Candoluminescence in transition-ion-activated oxide phosphors. Journal of the Electrochemical Society, 121: 142-145.

Ivey H., 1974 - Candoluminescence. Journal of Luminescence, 8: 271-306.

Nichols E.L., Howes H.L. \& Wilber D.T., 1928 Cathodoluminescence and the luminescence of incandescent solids. Carnegie Institution of Washington Publication 384: 227-350.

Shopov Y.Y., 2004 - 20 years of speleothem paleoluminescence records of environmental changes: an overview. International Journal of Speleology, 33: $5-17$.

Sweet J.R., White W.B., Henisch H.K. \& Roy R., 1970 - Chemically stimulated luminescence in rare earth oxides. Physics Letters, 33A: 195-197.

WhiteW.B., 1990-Photoluminescence, candoluminescence, and radical recombination luminescence of minerals. In: Coyne L.M., McKeever S.W.S. \& Blake D.F. (Eds.), Spectroscopic characterization of minerals and their surfaces. American Chemical Society Symposium Series 415: 118-134. 